\title{
COLOR DIFFERENCES OF PINE AND EUCALYPT WOODS MEASURED BY MICROFLASH-200 ${ }^{\circledR}$
}

\author{
Krisdianto $^{1}$
}

\begin{abstract}
It is not easy to define color because it refers to psychological response of human. As a result, perception of color achieved by people is relatively different. Wood color plays an important role in timber processing and it is an important consideration in wood identification. Each wood species has specific color and it becomes the species characteristic. Colors in wood are highly variable and unique features. Characteristics of wood color are influenced by extractive materials and moisture contents present on it. A standard of color measurement has been developed and it is called CIE model. The standard was developed to be completely independent of any devices and was based as closely as possible on human observation in color. CIELAB system is one of the simplest and most practical color measurement methods. The system has been used in one of the color measurement devices developed by Data Color International that is Microflash- $200^{\circledR}$. This research was aimed at translating interpretation of wood color by human eye into mathematical values so that scientific measurement of wood color can be studied. The measured wood color were 10 species of pines and 10 species of eucalypts woods in dry condition. The results showed that the two groups had different average of $\mathrm{L}^{*}$, $a^{*}$ and $b^{*}$ values. The average of $\mathrm{L}^{*}$ for pine was 70.77 , while eucalypt group made up to 52.40 . It means that eucalypt group is darker than pine group. For a* value, pine group mean value is 20.23 , whereas eucalypt group touches 19.11. In other words, pine and eucalypt group have an approximately similar redness. The $b^{*}$ value average for pine and eucalypt groups are 43.40 and 29.07 , respectively. This value means that pine group is more yellow than eucalypt group.
\end{abstract}

Keywords: Wood color, perception, measurement, Microflash-200 ${ }^{\circledR}$, pine, eucalypts

\section{INTRODUCTION}

Defining color is not easy because it is not physically real. It refers to the pshychological response of eye-brain combination to light waves falling upon the light-sensitive retina, which composes the inner surface of the eye. Sensitivity of the eye to color depends not only upon the light intensity, but also upon which area of the retina is being stimulated (Tilley, 1999). This condition causes different interpretation of color achieved by people.

Principally, there are three elements that build interpretation of color to the human eyes. These elements, which are known as triplet values, include the light source, the object and the observer. In order to measure the color scientifically, all of the elements must be measured in a standard condition (Boardman et al., 1992). Despite the complexity of the concept of color, all colors can be precisely specified by three parameters. These are hue, saturation and lightness. Hue corresponds to the wavelength or frequency of the radiation. The hue is given

${ }^{1}$ Forest Products Research and Development Center, Jalan Gunung Batu No. 5, Bogor.

Email: krisdianto@dephut.go.id 
a color name such as red or yellow. Saturation or chroma represents the amount of white light into the hue. Lightness, brightness or value describes the intensity of the color, the number of photons reaching the eye (Chrisment, 1998).

Color in a wood is a highly variable and unique feature. Characteristic of wood color is influenced by the presence of extractive materials (Jane, 1970). The more the extractive materials, the darker the timber. This fact can be seen from color difference between sapwood and heartwood. Accumulation of extractive in heartwood, make it darker than sapwood. Timber color is also induced by its moisture content. The higher the moisture content in a timber, the stronger the color will be. Another factor that determine wood color is the length of time on which wood surfaces have been exposed to air or sunlight. The longer wood exposed to the sunlight the lighter the wood color (Ilic, 1990).

Wood color plays an important role in timber processing. In a pulp industry, for example, wood color associates with extractive content. The darker the color of wood, the greater the extractives content. In a pulp processing, darker timber, which means high in extractives content gives low yields of pulp. Pulpwood from lightly colored tree will be superior to that of darker colored species of similar density and fibre dimensions (Schimleck and Michell, 1997).

Natural timber color is also one of the important considerations in wood identification (Boardman et al., 1992). Each wood species has specific color that becomes species characteristics. There are groups of wooden species that have dark color, such as ebony (Diospyros celebica), ulin (Eusideroxylon zwager), johar (Anthocephalus cadamba) and sonokeling (Pterocarpus indicus), while those of light colored include pine (Pinus spp.), sungkai (Peronema canescens), pulai (Alstonia scholaris) and gmelina (Gmelina arborea). Mahogany that has specific red color was popularly known as red wood.

Color is one of the important parameters for wood identification. Wood colors might be brown, white, yellow, brown or reddish-brown, or a tint in between. Due to its variability, wood color is not easy to define, especially if it is in intermediate colors. In 1990, Ilic has classified wood color into ten color standards to assist with color assessment. The color standards consist of straw, yellow-brown, brown, orange-brown, pinkish-brown, reddishbrown, chocolate-brown, greenish-brown, mauve-tint and bright-yellow. Figure 1. shows the ten of wood color standards. 


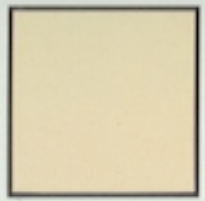

STRAW

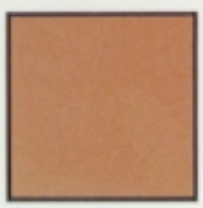

REDOISH-EROWN

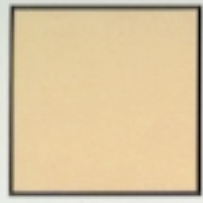

YELLW-BROWA

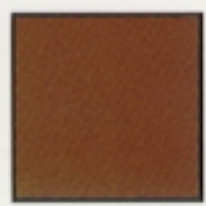

CHOCOLATE-BROWN

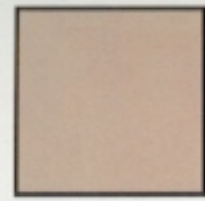

BROWh

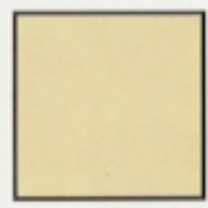

GREENISH-BROWH

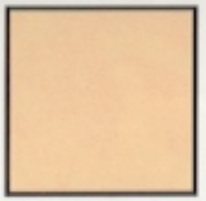

ORANGE-BROWN

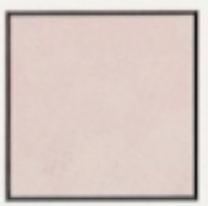

MAUVE TINT

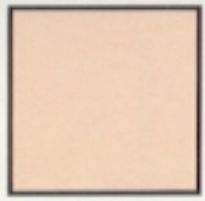

PINKISH-BROWN

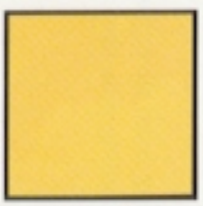

BRICHT YELLOW

Figure 1. Color chart for the assessment and matching of colors in wood (Source: Ilic, 1990).

Based on wood color standards, the specimen is matched into the closest standard. However, this color matching is not accurate enough. As mentioned before, the interpretation of color highly depends on humans eye observation and lighting condition. This fact shows that an accurate standard is needed to measure wood color (Nishino et al., 1998).

The developed general standard for color measurement is called Commision Internationale de l'Eclairage (CIE) model. The derived model response to various concerns, such as textile and automotive industry. The standards were developed to be completely independent of any devices and were based as closely as possible on human observation in color. Unlike the RGB and CYMK color models, Lab color or known as CIELAB is designed to approximate human vision. It aspires to perceptual uniformity. The three basics coordinates represent the lightness of the color $\left(\mathrm{L}^{*}, \mathrm{~L}^{*}=0\right.$ yields black and $\mathrm{L}^{*}=100$ indicates white), its positions between red/magenta and green ( $\mathrm{a}^{*}$, negative value indicate green, while positive values indicate magenta) and its position between yellow and blue ( $b^{*}$, negative values indicate blue and positie values indicate yellow). CIELAB system is one of the simplest and most practical color measurement method as long as colorimeter instrument is available. In the last ten years, Data Color International has developed colorimetric measuring instrument. One of them is Microflash-200 ${ }^{\circledR}$, which was designed based on CIE standard sources (1931) and the CIE observer standard 2 field of vision (1931) and 10 field of vision (XYZ, 2001).

Microflash $-200^{\circledR}$ is believed to be a stable measurement which has capability of repeatable measurements with high level of accuracy. This tool is also faster, lighter and smaller than other tools. It offers capability of analyzing diverse samples, more flexibility in the processing of information and easy use, as well as less cost.

This research was aimed at translating interpretation of wood color by human eye into mathematical values, so that wood color measurement can be scientifically defined. The tool used in this research was the one developed by the CIE system called Microflash- $200^{\circledR}$. 


\section{MATERIALS AND METHODS}

Measured wood samples in this study were 10 species of pine woods (Pinus sp.) and 10 species of eucalypt woods (Eucalyptus sp.), which were collected from wood collection of Creswick School of Forestry, Australia. In order to have similar condition of finished product, samples were measured in air dry condition.

Specimens were measured using Microflash $-200^{\circledR}$ in CIE standard, which were mostly implemented by color observer for solid material. The standard of illuminant A and the standard observer 10 were used. Illuminant A represented the light source from a tungsten lamp at $2856 \mathrm{~K}$, whereas the standard observer 10 meant that an observer viewed the sample at the angle of 10 degree. The diameter of sensor head was $6 \mathrm{~mm}$ (SAV = small area view). Every specimen was measured 10 times in tangential surfaces of the plank (Figure 2). The final colourimeter value every species was the average of measurement.

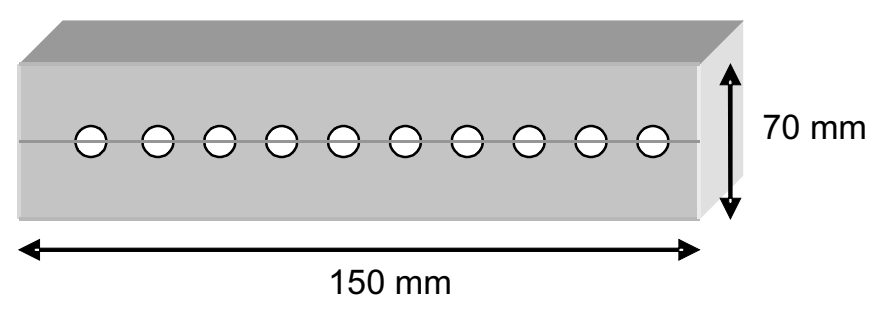

Figure 2. Ten measurements of the wood plank

\section{RESULTS AND DISCUSSION}

The results of 20 species wood color measurement, values are averaged from 10 times measurements (Table 1). 
Table 1. Color measurement results of wood species in air dry condition

\begin{tabular}{clccc}
\hline \multirow{2}{*}{ No. Species } & & \multicolumn{3}{c}{ Color Dimension } \\
\cline { 3 - 5 } & & L* & a* & b* \\
\hline 1 & Pinus palustris & 56.464 & 25.660 & 41.81 \\
2 & Pinus resinosa & 71.984 & 20.068 & 43.48 \\
3 & Pinus halepensis & 72.464 & 19.168 & 43.108 \\
4 & Pinus canariensis & 76.248 & 18.282 & 45.022 \\
5 & Pinus radiate & 71.064 & 19.356 & 42.736 \\
6 & Pinus sylvestris & 72.094 & 20.306 & 45.554 \\
7 & Pinus strobes & 77.802 & 17.554 & 38.37 \\
8 & Pinus echinata & 69.172 & 21.242 & 46.502 \\
9 & Pinus taeda & 69.31 & 21.388 & 45.67 \\
10 & Pinus pinnaster & 71.112 & 19.328 & 41.72 \\
11 & Eucalyptus muellerana & 53.643 & 13.969 & 27.275 \\
12 & Eucalyptus grandis & 61.642 & 22.496 & 31.436 \\
13 & Eucalyptus microcorys & 61.902 & 13.594 & 29.836 \\
14 & Eucalyptus propinqua & 45.374 & 23.918 & 30 \\
15 & Eucalyptus dives & 50.462 & 18.362 & 27.736 \\
16 & Eucalyptus oblique & 55.096 & 17.152 & 32.342 \\
17 & Eucalyptus maculate & 53.6 & 19.22 & 33.444 \\
18 & Eucalyptus viminalis & 65.098 & 19.038 & 30.334 \\
19 & Eucalyptus gummifera & 37.36 & 22.506 & 23.35 \\
20 & Eucalyptus crebra & 39.798 & 20.862 & 24.996 \\
\hline
\end{tabular}

Remarks: $L^{*}=$ the lightness of the color

$\mathrm{a}^{*}=$ position between magenta and green (negative values indicate green while positive values indicate magenta)

$\mathrm{b}^{*}=$ position between yellow and blue (negative values indicate blue and positive values indicate yellow)

The values indicated that, $\mathrm{L}^{*}, \mathrm{a}^{*}$ and $\mathrm{b}^{*}$ have a different pattern. The differences can be seen in Figure $3 a$ and $b$. 

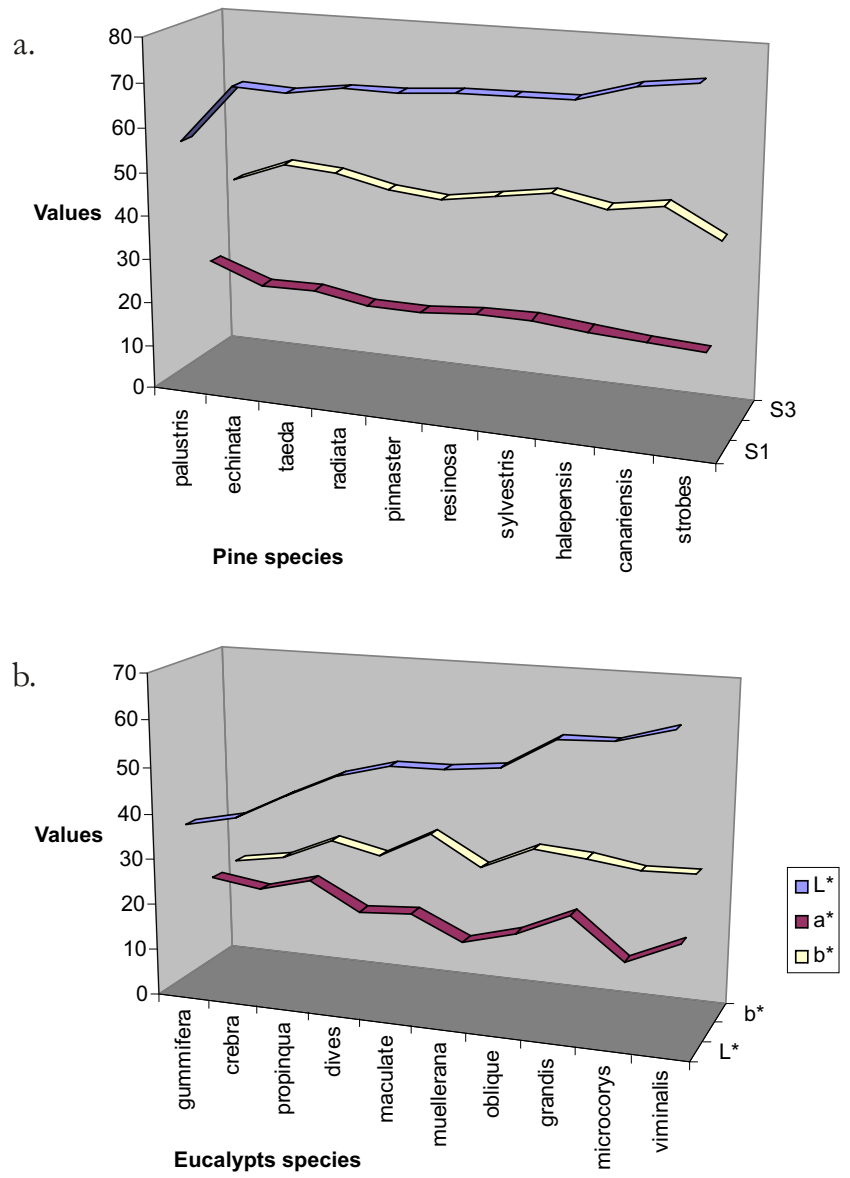

Figure 3. Color value $\mathrm{L}^{*} \mathrm{a}^{*} \mathrm{~b}^{*}$ of pine species (a) and eucalypts species (b)

As seen in Figure 3, the measurement of wood color of the two groups of the wood resulted in different average $L^{*}, a^{*}$ and $b^{*}$ values. Generally, pine timber species have higher $\mathrm{L}^{*}$ and $\mathrm{b}^{*}$ value than eucalypts species, while $\mathrm{a}^{*}$ values are approximately similar on both groups. Among pine wood species, $P$. palustris has the lowest $L^{*}$ value, while $P$. canariensis has the highest value of $\mathrm{L}^{*}$ value. In human perception $P$. palustris is darker than $P$. canariensis. In the eucalypts groups, E. gummifera has the lowest $L^{*}$ value, while E. viminalis has the lowest value. In other words, E. viminalis is darker than E. gummifera. The measurement result in comparison between two groups is shown in Figure 4. 

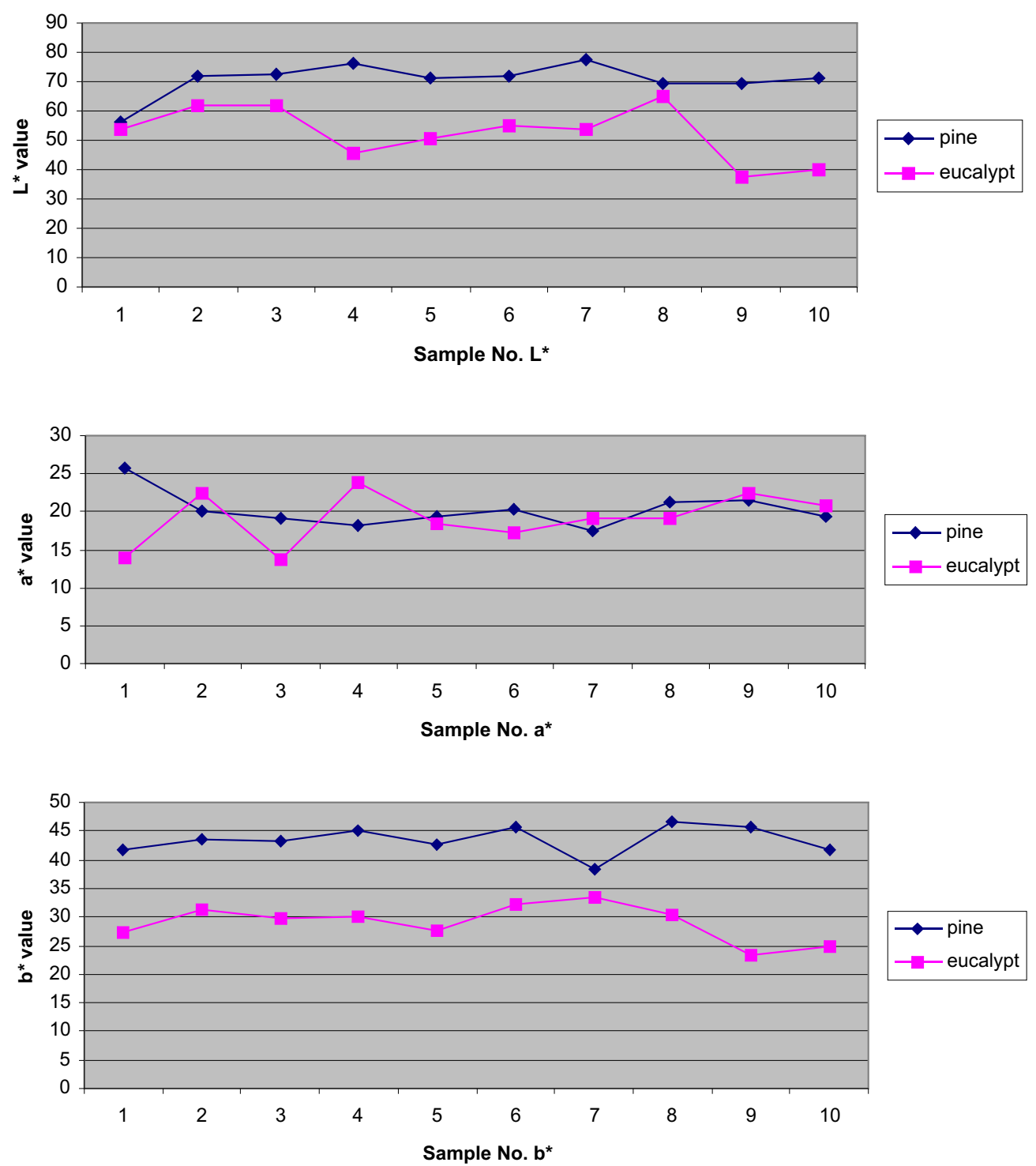

Figure 4. Wood color of pine and eucalypt

Remarks: $\left(\mathrm{L}^{*}\right)$ Lightness values, $\left(\mathrm{a}^{*}\right)$. Position between red and green, $\left(\mathrm{b}^{*}\right)$ Position between yellow and blue

The three basic coordinates represent the lightness of the color $\left(L^{*}\right)$, its position between red or magenta and green $\left(a^{*}\right)$ and its position between yellow and blue $\left(b^{*}\right)$. The value of $\mathrm{L}^{*}=0$ yields black and $\mathrm{L}^{*}=100$ indicates white, while negative value of $\mathrm{a}^{*}$ indicates green and positive indicates magenta. The negative value of $\mathrm{b}^{*}$ indicates blue and positive 
values indicates yellow. The measurement shows that the two groups had different average of $L^{*}, a^{*}$ and $b^{*}$ values. The average of $L^{*}$ for the pine sample group is 70.77 , while eucalypt group makes up to 52.40. It means that eucalypt group is darker than pine group. For a* value, pine group mean value is 20.23 , whereas eucalypt group touches 19.11 . In other words, pine and eucalypt group have an approximately similar redness. The $b^{*}$ value average for pine and eucalypt groups are 43.40 and 29.07 , respectively. This value means that pine group is more yellow than eucalypt group.

As mentioned before, Lab system is designed to approximate human vision. In comparison with human eye, the perception is easily put on $\mathrm{L}^{*}$ value, while the $\mathrm{a}^{*}$ and $\mathrm{b}^{*}$ value are hard to identify. In other word, human perception point out euclaypts group is darker than pine, while the redness and yellowness is different to any people.

The result of paired sample t-test of $\mathrm{L}^{*}, \mathrm{a}^{*}$ and $\mathrm{b}^{*}$ value is shown in Table 2.

Table 2. Paired samples t-test result

\begin{tabular}{lccccc}
\hline & Mean & $\begin{array}{c}\text { Std. } \\
\text { Deviation }\end{array}$ & $\begin{array}{c}\text { Std. Error } \\
\text { Mean }\end{array}$ & t & $\begin{array}{c}\text { Sig. } \\
\text { (2-tailed) }\end{array}$ \\
\hline Pair 1 L* value & 18.4279 & 5.553969 & 1.756319 & 10.492 & $0.000^{* *}$ \\
Pair 2 a* value & 1.1235 & 3.113963 & 0.984722 & 1.141 & $0.283^{* *}$ \\
Pair 3 b* value & 14.3223 & 4.211418 & 1.331767 & 10.754 & $0.000^{* *}$ \\
\hline
\end{tabular}

Remarks : ** significantly differences

The paired sample t-test shows the $\mathrm{L}^{*}$ and $\mathrm{b}^{*}$ value is significantly different between pine and eucalypt groups, while a* value is not significantly different between those two groups. In other words, the lightness and yellowish value of pine and eucalypt wood are significantly different, while redness value is approximately identical.

\section{CONCLUSIONS}

1. Wood color is not easy to be defined because it is not a physical reality. It refers to the psychological response of the eye-brain combination to light waves falling upon the lightsensitive retina, which makes up the inner surface of the eye. As a result, color measurement has been developed in order to standardized color. One of the equipment developed was Microflash-200 ${ }^{\circledR}$.

2. Mathematical values of wood color obtained using CIE system are also substantive to justify a particular species of wood during wood identification process.

3. The average of $\mathrm{L}^{*}$ value for pine group is 70.77 , while eucalypt makes up to 52.40 . It means that eucalypt group is darker than pine group. For $a^{*}$ value, pine group mean value is 20.23, whereas eucalypt group touches 19.11. In other words, pine and eucalypt group have an approximately similar redness. The $b^{*}$ value average for pine and eucalypt groups are 43.40 and 29.07 , respectively. This value means that pine group is more yellow than eucalypt group. 


\section{ACKNOWLEDGEMENT}

This article was presented in the National Seminar of MAPEKI VIII, 3 - 5 September 2005, Tenggarong, East Kalimantan, Indonesia.

\section{REFERENCES}

Boardman, B.E., J.F. Senft, G.P. McCabe and C.M. Ladisch. 1992. Colorimetric analysis in grading black walnut veneer. Wood and Fiber Science 24: 99-107.

Chrisment, A. 1998. Color and Colorimetry. Data Color International, Sydney, Australia. 30 pp.

Ilic, J. 1990. The CSIRO Macro key for Hardwood Identificaton. Division of Forestry and Forest Products, CSIRO, Melbourne, Australia. $125 \mathrm{pp}$.

Jane, F.W. 1970. The Structure of Wood. Adam \& Charles Black, London.427 pp.

Nishino Y., G. Janin, B. Chanson, G. Detienne, J. Gril and B. Thibaut. 1998. Colorymetry of wood specimens from French Guiana. Journal of Wood Science 44: 3 - 8.

Schimleck, L.R. and A.J. Michell. 1997. Measurement of Wood Colour by Reflectance Spectroscopy in the Visible and Near-Infrared Regions. Research Report of CRC Publications Committee, Melbourne. 78 pp.

Tilley, R. 1999. Colour and the Optical Properties of Materials. An exploration of relationship between light, the optical properties of material and colour. Cardiff University. John Wiley \& Son, Ltd, England. 342 pp.

XYZ Australia Pty Ltd. 2001. Controlling Color A Practical Introduction. Colour training article, Sydney, Australia. 58 pp. 